\title{
CONVECTIVE HEAT TRANSFER AND FLOW STABILITY IN ROTATING DISK CVD REACTORS
}

\author{
William S. Winters and Greg H. Evans \\ Computational Reactive Processes Department \\ Sandia National Laboratories \\ P.O. Box 969 \\ Livermore, California 94551-0969 \\ USA \\ Ralph Greif \\ Mechanical Engineering Department \\ University of California \\ Berkeley, California 94720-1740 \\ USA
}

\section{ABSTRACT}

The flow and heat transfer of $\mathrm{NH}_{3}$ and $\mathrm{He}$ have been studied in a rotating disk system with applications to chemical vapor deposition reactors. Influence of the important operating parameters were studied numerically over ranges of the primary dimensionless variables: the spin Reynolds number, $\mathrm{Re}_{\omega}$, the disk mixed convection parameter, $\mathrm{MCP}_{\mathrm{d}}$ and a new parameter, the wall mixed convection parameter, $\mathrm{MCP}_{\mathrm{w}}$. Inlet velocities were set to the corresponding infinite rotating disk asymptotic velocity. Results were obtained primarily for $\mathrm{NH}_{3}$. Results show that increasing $\mathrm{Re}_{\omega}$ from 314.5 to 3145 increases the uniformity of the rotating disk heat flux and results in thinner thermal boundary layers at the disk surface. At $\mathrm{Re}_{\mathrm{c}}=314.5$, increasing $\mathrm{MCP}$ do 15 leads to significant departure from the infinite disk result with nonuniform disk heat fluxes and recirculating flow patterns. At $\mathrm{Re}_{\omega}=$ 3145 , the results are closer to the infinite disk for $\mathrm{MCP}_{\mathrm{d}}$ up to 15. For large values of $\mathrm{MCP}_{\mathrm{w}}$, the flow recirculates and there is significant deviation from the infinite disk result. The influence of $\mathrm{MCP}_{\mathrm{w}}$ on flow stability is increased at larger $\mathrm{MCP}_{\mathrm{d}}$ and lower $\mathrm{Re}_{\omega}$. The results show that because of variable transport properties, the flow of $\mathrm{NH}_{3}$ is less stable than that of $\mathrm{He}$ as $\mathrm{MCP}_{\mathrm{d}}$ is increased for $\mathrm{MCP}_{\mathrm{w}}=0$ and $\operatorname{Re}_{\omega}=314.5$.

\section{INTRODUCTION}

The chemical vapor deposition (CVD) process is widely used for growing epitaxial layers on heated substrates. The uniformity of layers grown often depends on a stable, uniform and continuous flow of reacting species to the growth surface.

Deviations from the ideal flow behavior in a CVD reactor may result from the effects of variable properties, reactor geometry, gas flow rates, thermal boundary conditions, and variations in gas composition at the reactor inlet. Previous studies by Evans and Greif (1987),

Patnaik et al. (1989), and Chou and Gong (1994) have examined these effects for a single component gas in a RDR. Palmateer et al. (1987) and Winters et al. (1997) have examined convective instabilities under isothermal conditions resulting from binary gas mixing at the reactor inlet.

The present work examines the effects of gas properties and reactor wall temperature; a new parameter for characterizing RDR flows is introduced, namely, a wall mixed convection parameter, $\mathrm{MCP}_{\mathrm{w}}$. In addition, the effects of variable transport properties is shown by comparing results obtained for $\mathrm{He}$ and $\mathrm{NH}_{3}$ gas flows. Results are presented in terms of common RDR flow parameters including the spin Reynolds number, $R_{\omega}$, and the disk mixed convection parameter $\mathrm{MCP}_{\mathrm{d}}$. The wall mixed convection parameter, $\mathrm{MCP}_{\mathrm{w}}$, is varied to study the effect of reactor wall temperature on flow stability and convective heat transfer. The reactor performance is quantified by examining radial variations in the disk heat flux, normalized by the ideal infinite rotating disk heat flux (see e.g. Evans and Greif (1988)).

\section{MODEL}

A cylindrical reactor of radius $\bar{r}_{\mathrm{o}}$ and height $\overline{\mathrm{H}}$ contains a spinning disk of radius $\bar{r}_{d}$ located a distance $\bar{h}$ from the top inlet ( $c f$. Fig. 1). The incoming flow consists of a single component ideal gas, either $\mathrm{NH}_{3}$ or $\mathrm{He}$, with a uniform inlet velocity, $\bar{u}_{\text {in }}$.

The dimensionless, steady, variable property, cylindrical, axisymmetric conservation equations of mass, momentum and energy for low Mach number flow, neglecting viscous dissipation and $D p / D t$ (pressure work) in the energy equation, are:

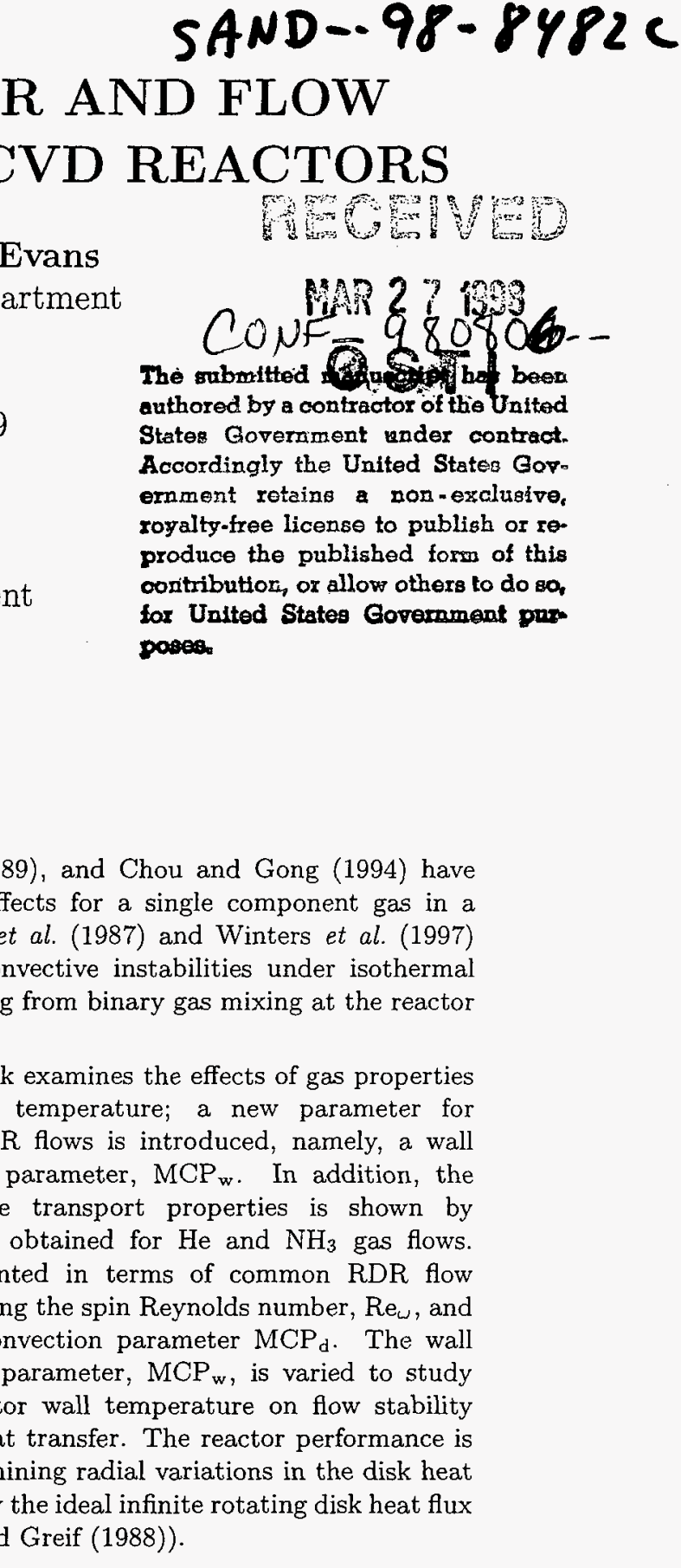

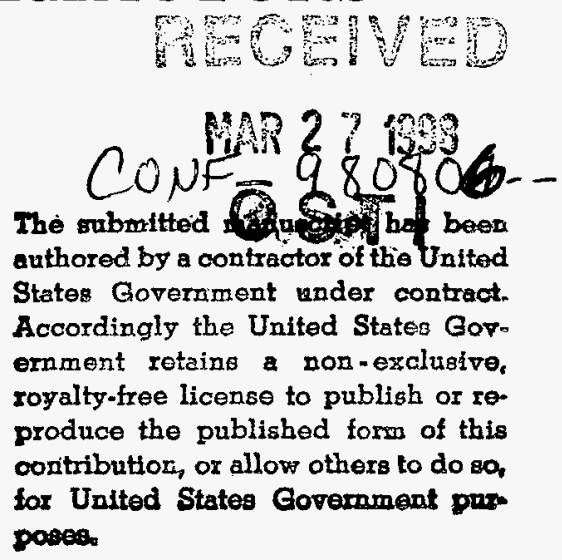




\section{DISCLAIMER}

This report was prepared as an account of work sponsored by an agency of the United States Government. Neither the United States Government nor any agency thereof, nor any of their employees, make any warranty, express or implied, or assumes any legal liability or responsibility for the accuracy, completeness, or usefulness of any information, apparatus, product, or process disclosed, or represents that its use would not infringe privately owned rights. Reference herein to any specific commercial product, process, or service by trade name, trademark, manufacturer, or otherwise does not necessarily constitute or imply its endorsement, recommendation, or favoring by the United States Government or any agency thereof. The views and opinions of authors expressed herein do not necessarily state or reflect those of the United States Government or any agency thereof. 


$$
\begin{aligned}
& \frac{1}{r} \frac{\partial}{\partial r}\left(r \rho v u-\frac{r \mu}{\operatorname{Re}_{\omega}} \frac{\partial u}{\partial r}\right)+\frac{\partial}{\partial x}\left(\rho u u-\mu \frac{\partial u}{\partial x}\right)= \\
& -\frac{\partial p_{m}}{\partial x}+\frac{\mathrm{Gr}_{\mathrm{d}}}{\operatorname{Re}_{\omega}{ }^{3 / 2}} \frac{\rho_{d}}{\left(1-\rho_{d}\right)}(1-\rho)+\frac{1}{r} \frac{\partial}{\partial r}\left(r \mu \frac{\partial v}{\partial x}\right)+ \\
& \frac{\partial}{\partial x}\left\{\mu \frac{\partial u}{\partial x}-\frac{2 \mu}{3}\left[\frac{1}{r} \frac{\partial(r v)}{\partial r}+\frac{\partial u}{\partial x}\right]\right\}
\end{aligned}
$$$$
\frac{1}{r} \frac{\partial}{\partial r}\left(r \rho v v-\frac{r \mu}{\operatorname{Re}_{\omega}} \frac{\partial v}{\partial r}\right)+\frac{\partial}{\partial x}\left(\rho u v-\mu \frac{\partial v}{\partial x}\right)=
$$$$
-\frac{1}{\operatorname{Re}_{\omega}} \frac{\partial p_{m}}{\partial r}+r \rho f^{2}+\frac{1}{\operatorname{Re}_{\omega}} \frac{1}{r} \frac{\partial}{\partial r}\left\{r \mu \left[\frac{\partial v}{\partial r}-\right.\right.
$$$$
\left.\left.\frac{2}{3}\left(\frac{1}{r} \frac{\partial(r v)}{\partial r}+\frac{\partial u}{\partial x}\right)\right]\right\}-\frac{1}{\operatorname{Re}_{\omega}} \frac{\mu}{r}\left\{\frac{2 v}{r}-\frac{2}{3}\left[\frac{1}{r} \frac{\partial(r v)}{\partial r}\right.\right.
$$$$
\left.\left.+\frac{\partial u}{\partial x}\right]\right\}+\frac{1}{\operatorname{Re}_{\omega}} \frac{\partial}{\partial x}\left(\mu \frac{\partial u}{\partial r}\right)
$$$$
\frac{1}{r} \frac{\partial}{\partial r}\left(r \rho v f-\frac{r \mu}{\operatorname{Re}_{\omega}} \frac{\partial f}{\partial r}\right)+\frac{\partial}{\partial x}\left(\rho u f-\mu \frac{\partial f}{\partial x}\right)=
$$$$
-\frac{2 \rho v f}{r}+\frac{1}{\operatorname{Re}_{\omega}} \frac{2 \mu}{r} \frac{\partial f}{\partial r}
$$

$$
\begin{aligned}
& \frac{1}{r} \frac{\partial}{\partial r}\left(r \rho v T-\frac{r k}{c_{p} \operatorname{Re}_{\omega} \operatorname{Pr}} \frac{\partial T}{\partial r}\right)+\frac{\partial}{\partial x}(\rho u T- \\
& \left.\frac{k}{c_{p} \operatorname{Pr}} \frac{\partial T}{\partial x}\right)=\frac{k}{c_{p}^{2} \operatorname{Pr}}\left[\frac{1}{\operatorname{Re}_{\omega}} \frac{\partial T}{\partial r} \frac{\partial c_{p}}{\partial r}+\frac{\partial T}{\partial x} \frac{\partial c_{p}}{\partial x}\right]
\end{aligned}
$$

where $f \equiv w / r$ in equation (4); $u, v, w$ are the dimensionless axial, radial, and circumferential velocity components, respectively. The dimensionless parameters in equations (1-5) are: the disk Grashof number, $\mathrm{Gr}_{d}=$ $\bar{g}\left(\bar{\rho}_{\text {in }}-\bar{\rho}_{d}\right) \bar{r}_{d}{ }^{3} /\left(\bar{\rho}_{d} \bar{\nu}_{\text {in }}{ }^{2}\right)$, the spin Reynolds number, $\operatorname{Re}_{\omega}=$ $\bar{r}_{d}^{2} \bar{\omega} / \bar{\nu}_{\text {in }}$, and the Prandtl number, $\operatorname{Pr}=\bar{c}_{p_{\text {in }}} \bar{\mu}_{\text {in }} / \bar{k}_{\text {in }}(\bar{\omega}$ is the disk spin rate; $\bar{\nu}, \bar{\mu}, \bar{\rho}, \bar{c}_{p}$, and $\bar{k}$ are the kinematic and dynamic viscosities, density, specific heat at constant pressure, and thermal conductivity, respectively). The properties are normalized based on their values at the temperature at the reactor inlet, $\bar{T}_{\mathrm{in}}$. The usual scaling (Evans and Greif, 1987) for a rotating disk has been used: $\sqrt{\bar{\omega} \bar{\nu}_{\text {in }}}$ for the axial component of velocity, $\bar{r}_{d} \bar{\omega}$ for the radial and circumferential components of velocity, $\sqrt{\bar{\nu}_{\text {in }} / \bar{\omega}}$ for the axial coordinate, and $\bar{r}_{d}$ for the radial coordinate, where symbols with overbars represent dimensional quantities. The dimensionless temperature is $T=\left(\bar{T}-\bar{T}_{\text {in }}\right) /\left(\bar{T}_{\mathrm{d}}-\bar{T}_{\text {in }}\right)$.

The boundary conditions are:

$$
\begin{array}{lll}
x=0 & 0 \leq r \leq 1 & u=v=0, f=T=1 \\
r=A & h-H \leq x \leq h & u=v=f=0, T= \\
& & -\frac{M C P_{w}}{M_{\mathrm{d}}}\left(u_{\text {in }} 3 / \operatorname{Re}_{\text {in }}\right) \\
r=1 & h-H \leq x \leq 0 & u=v=f=\partial T / \partial r=0 \\
r=0 & 0 \leq x \leq h & \partial u / \partial r=\partial f / \partial r= \\
& & \partial T / \partial r=v=0 \\
x=h & 0 \leq r \leq A & v=f=T=0, \\
& & u=\operatorname{Re}_{\text {in }} /\left(2 A \sqrt{\operatorname{Re}_{\omega}}\right)
\end{array}
$$

where the inlet Reynolds number, $\operatorname{Re}_{\text {in }}=2 \bar{r}_{o} \bar{u}_{\text {in }} / \bar{\nu}_{\text {in }}$, $A=\bar{r}_{\mathrm{o}} / \bar{r}_{\mathrm{d}}$, and for an ideal gas, the disk Grashof number, $\mathrm{Gr}_{\mathrm{d}}=\bar{g}\left(\bar{T}_{\mathrm{d}}-\bar{T}_{\text {in }}\right) \bar{r}_{\mathrm{d}}{ }^{3} /\left(\bar{T}_{\text {in }} \bar{\nu}_{\text {in }}^{2}\right)$, the wall Grashof number, $\mathrm{Gr}_{\mathrm{w}}=\bar{g}\left(\bar{T}_{\mathrm{in}}-\bar{T}_{\mathrm{w}}\right)\left(2 \bar{r}_{\mathrm{o}}\right)^{3} /\left(\bar{T}_{\mathrm{in}} \bar{\nu}_{\text {in }}^{2}\right)$, the disk mixed convection parameter, $\mathrm{MCP}_{\mathrm{d}}=\mathrm{Gr}_{\mathrm{d}} / \mathrm{Re}_{\omega}{ }^{3 / 2}$, and the wall mixed convection parameter, $\mathrm{MCP}_{\mathrm{w}}=$ $\mathrm{Gr}_{\mathrm{w}} / \operatorname{Re}_{\mathrm{in}}{ }^{2}$. In the current study, $\operatorname{Re}_{\text {in }}$ is not an independent parameter because we consider only cases where the inlet velocity is set equal to the asymptotic velocity for an infinite rotating disk: $\bar{u}_{\text {in }}=C \sqrt{\bar{\omega} \bar{\nu}_{\text {in }}}$, which gives $u_{\text {in }}=C$, where $C$ is a function of the inlet temperature, $\bar{T}_{\mathrm{in}}$, the disk temperature $\bar{T}_{\mathrm{d}}$ and the gas (Evans and Greif, 1987). Thus in this study, $\operatorname{Re}_{\text {in }}=2 A C \sqrt{\operatorname{Re}_{\omega}}$, and the dimensionless reactor wall temperature is $T_{\mathrm{w}}=-\left(\mathrm{MCP}_{\mathrm{w}} / \mathrm{MCP}_{\mathrm{d}}\right)\left[C^{2} /\left(2 A \sqrt{\mathrm{Re}_{\omega}}\right)\right]$. Fully developed conditions are applied at the outflow boundary.

The equations are integrated over control volumes and discretized using the hybrid differencing scheme (Patankar, 1980). The SIMPLER method is used to determine the pressure, $p_{m}$. A sequential iterative line relaxation scheme is used to solve the equations. A more detailed description of the numerical method is given by Winters et al. (1996).

The results discussed here were obtained on a nonuniform grid of 80 by 40 control volumes in the $x$ and $r$ directions, respectively, between the inlet and the disk, with finer grid spacings near the rotating disk $(x=0)$. The control volumes were distributed over three computational regions (one bounded by the inlet and the disk, a second adjacent to the first bounded by the inlet and the beginning of the annular exit, and a third for the annular exit). A nonuniform grid of 25 by 10 control volumes in the $x$ and $r$ directions was used for the annular exit. Calculations made on a coarser grid resulted in disk heat flux differences of less than $5 \%$ for the two grid distributions. Furthermore, the fine grid resolution of the rotating disk boundary layer was deemed adequate because the results of the numerical calculations at the centerline $(r=0)$ differed from the similarity solution for the flow over an infinite rotating disk by less than $2 \%$.

\section{RESULTS AND DISCUSSION}

Results for the system shown in Fig. 1 are presented using the dimensionless groups defined in the previous section. Variations in the Prandtl number, Pr, were not considered since the Prandtl numbers for common carrier gases in RDRs are nearly equal ( $c f$. Table 1). This study also presents new results for the effects of variable properties by considering two common CVD gases, $\mathrm{NH}_{3}$ and He. Results were obtained for two spin Reynolds numbers which span a range characteristic of RDRs: $\operatorname{Re}_{\omega}=314.5$ and $\mathrm{Re}_{\omega}=3145$. For each spin Reynolds number, $\mathrm{MCP}_{\mathrm{d}}$ was increased from nearly zero to a level where significant departure from the ideal infinite rotating 
disk behavior was obtained. The wall mixed convection parameter, $\mathrm{MCP}_{\mathrm{w}}$, was varied from -30 to +30 ; negative values are for hotter walls relative to the inlet while positive values are for cooler walls relative to the inlet.

\section{The Ideal Reactor}

One measure of reactor flow suitability is how well the disk heat flux compares to the corresponding "ideal" infinite rotating disk heat flux, $\overline{\mathrm{q}}_{1 \mathrm{D}}$ which is defined as:

$$
\bar{q}_{1 \mathrm{D}}=\left[-\left.\bar{k} \frac{\partial \bar{T}}{\partial \bar{x}}\right|_{\bar{x}=0}\right]_{1 \mathrm{D}}
$$

Because RDRs have finite disk diameters, deviation from the ideal flow is unavoidable at the disk edges due to two-dimensional effects. For geometries like the one shown in Fig. 1, the disk heat flux usually exceeds the ideal value at the disk edges due the local flow acceleration which accompanies the flow into the narrow exit channel. However, under stable operating conditions, it is reasonable to expect the RDR flow to approximate the ideal flow over a large portion of the disk.

Fig. 2 illustrates reactor flow $\left(\mathrm{NH}_{3}\right)$ characteristics for $\operatorname{Re}_{\omega}=314.5, \mathrm{MCP}_{\mathrm{d}}=1.3$, and $\mathrm{MCP}_{\mathrm{w}}=0 \mathrm{Fig}$. 2(a) shows the reactor in cross-section with white streamlines superimposed over grey shaded temperature contours. Dark grey corresponds to the lowest temperature (inlet and cold walls) and light grey corresponds to the highest temperature (disk) in the flow field. A more detailed legend of contour values will not be presented because these plots are intended to demonstrate the qualitative nature of the flow even though the plots were generated from computed results. More quantitative information is presented in Fig. 2(b) which shows the heat flux distribution along the disk surface. The radial position is normalized by the disk radius $(9 \mathrm{~cm})$ and the heat flux is normalized by the ideal infinite rotating disk heat flux $\left(3.37 \times 10^{6} \mathrm{ergs} / \mathrm{s}-\mathrm{cm}^{2}\right)$ which was computed from the similarity solution (Evans and Greif, 1988).

The normalized heat flux plot of Fig. 2(b) shows excellent agreement between the 2-D model and the 1$\mathrm{D}$ result over $60 \%$ of the disk radius. Uniformity is increased to $90 \%$ when the spin Reynolds number is increased to 3145 while maintaining $\mathrm{MCP}_{\mathrm{d}}=1.3$, and $\mathrm{MCP}_{\mathrm{w}}=0$ (results not shown here). Increasing $\operatorname{Re}_{\omega}$ also produces a thinner thermal boundary layer at the disk and correspondingly higher heat flux.

The Influences of $\mathrm{MCP}_{\mathrm{d}}$ and $\mathrm{Re}_{\omega}$

Results were obtained for a range of $\mathrm{MCP}_{d}$ values (1.3-20) at two spin Reynolds numbers (314.5 and 3145) for $\mathrm{NH}_{3}$ flow and $\mathrm{MCP}_{\mathrm{w}}=0$. Fig. 3 shows reactor behavior for $\mathrm{MCP}_{d}$ values of 10 and 15 and $\mathrm{Re}_{\omega}=$ 314.5. Normalized disk heat flux distributions are shown in Fig. 3(c). At $\mathrm{MCP}_{d}=10$, some departure from the 1-D behavior is apparent; the magnitude has increased slightly but the distribution remains relatively uniform. At $\mathrm{MCP}_{\mathrm{d}}=15$ there is a recirculating flow that affects both the magnitude and uniformity of the disk heat flux. Further increases in $\mathrm{MCP}_{\mathrm{d}}$ cause stronger recirculations and correspondingly greater departure from the $1-D$ heat flux result. At $\operatorname{Re}_{\omega}=3145$, departure from 1-D behavior was less pronounced (less than $5 \%$ for $\mathrm{MCP}_{d}=15$ ) and no recirculations were observed but unsteady flow occurred for $\mathrm{MCP}_{d}>15$.

The Influence of $\mathrm{MCP}_{\mathrm{w}}$ and $\mathrm{Re}_{\omega}$

In order to determine the influence of wall temperature on reactor flow and heat transfer, the wall mixed convection parameter, $\mathrm{MCP}_{\mathrm{w}}$, was varied over a range typical for RDRs. The disk mixed convection parameter, MCP $\mathrm{d}$ was fixed at 5 and results were obtained for $\mathrm{NH}_{3}$ at the two spin Reynolds numbers (314.5 and 3145). Fig. 4 shows reactor flow and temperature for $\mathrm{MCP}_{\mathrm{w}}=$ $-30,0,+30$ and $\operatorname{Re}_{\omega}=314.5$. The corresponding disk heat flux profiles are shown in Fig. 5. For $\mathrm{MCP}_{\mathrm{w}}=-30$, the wall is hotter than the downward flowing gas, and a buoyancy induced recirculation develops near the reactor walls. This causes the downward flow to be channeled inward toward the reactor centerline; note the inward curvature of the streamlines in Fig. 4(a). This results in a slight increase in the disk heat transfer over the entire disk. Cooling the walls relative to the inlet $\left(\mathrm{MCP}_{\mathrm{w}}=+30\right)$ causes a downward sidewall flow that leads to a weak recirculation and reduced heat flux over the outer half of the disk. Similar calculations performed for $\mathrm{Re}_{\omega}=3145$ also exhibited flow recirculations but departure from 1-D heat flux behaviour was less as shown in Fig. 6 .

At higher values of $\mathrm{MCP}_{\mathrm{d}}$, variations in $M C P_{w}$ lead to greater departures from the 1-D behavior. Fig. 7 and Fig. 8 show results for $\mathrm{MCP}_{\mathrm{w}}$ of $-30,0,+30$ at $\mathrm{MCP}_{\mathrm{d}}=7$ and $\mathrm{Re}_{\omega}=3145$. The small increase in MCP from 5 to 7 results in a substantial increase in disk heat flux nonuniformity. Further increases in $\mathrm{MCP}_{d}$ lead to unsteady flows for $\mathrm{MCP}_{\mathrm{w}}=+30$.

\section{The Influence of Variable Gas Properties}

Table 1 shows transport property and Prandtl number variations for common RDR gases evaluated at 400 and $1300 \mathrm{~K}$. Prandtl numbers for the common carrier gases are nearly equal and constant over the temperature range considered here. Hence, if it could be shown that variations of the transport properties with temperature are unimportant, the results presented in the previous sections would apply for all the common carrier gases.

To determine the influence of variable transport properties, several calculations were repeated using $\mathrm{He}$ in place of $\mathrm{NH}_{3}$. Note that the largest variation in transport properties for the gases shown in Table 1 occurs for $\mathrm{NH}_{3}$, the least for He. Fig. 9 shows flow fields and disk heat flux profiles for $\mathrm{He}$ and $\mathrm{NH}_{3}$ for $\mathrm{Re}_{\omega}=314.5, \mathrm{MCP}_{\mathrm{w}}=0$ and $\mathrm{MCP}_{\mathrm{d}}=15$. Using the asymptotic velocity caused $R e_{\text {in }}$ for the $\mathrm{NH}_{3}$ and He calculations to be slightly different (47 for $\mathrm{NH}_{3}$ and 42 for $\mathrm{He}$ ). $\mathrm{NH}_{3}$ flow exhibits significant departure from 1-D flow with nonuniform heat transfer and strong recirculating flow. In contrast, the $\mathrm{He}$ flow resembles the 1-D result with only a slight nonuniformity in the disk heat flux. At $\mathrm{MCP}_{\mathrm{d}} \leq 10$ both gases exhibit 1-D behavior (results not shown here). 


\section{CONCLUSIONS}

The results for $\mathrm{NH}_{3}$ show that increasing $\mathrm{Re}_{\omega}$ from 314.5 to 3145 increases the uniformity of the rotating disk heat flux and results in thinner thermal boundary layers at the disk surface. At $\operatorname{Re}_{\omega}=314.5$, increasing $\mathrm{MCP}_{\mathrm{d}}$ to 15 leads to significant departure from the 1-D infinite disk result with nonuniform disk heat fluxes and recirculating flow patterns; the flow becomes increasingly complex at larger values of $M C P_{d}$. At the larger value of $R_{\omega}$ of 3145 , the results are closer to the 1-D infinite disk for $M_{C} P_{d}$ up to 15.

For large negative (hot walls) and positive (cold walls) values of $M C P_{w}$, the flow recirculates and there is significant deviation from the one-dimensional result; the nonuniformities occur at $\operatorname{Re}_{\omega}=314.5$ and 3145 . The sensitivity to large variations in $\mathrm{MCP}_{\mathrm{w}}$ is increased at larger $\mathrm{MCP}_{\mathrm{d}}$ and lower $\mathrm{Re}_{\omega}$. Substituting $\mathrm{He}$ for $\mathrm{NH}_{3}$ for several calculations demonstrated the strong influence due to the variable transport properties. For $\mathrm{He}$ (smaller variation in transport properties), the disk thermal boundary layers tended to be thinner and the flow was more stable over a larger range of $\mathrm{MCP}_{\mathrm{d}}$.

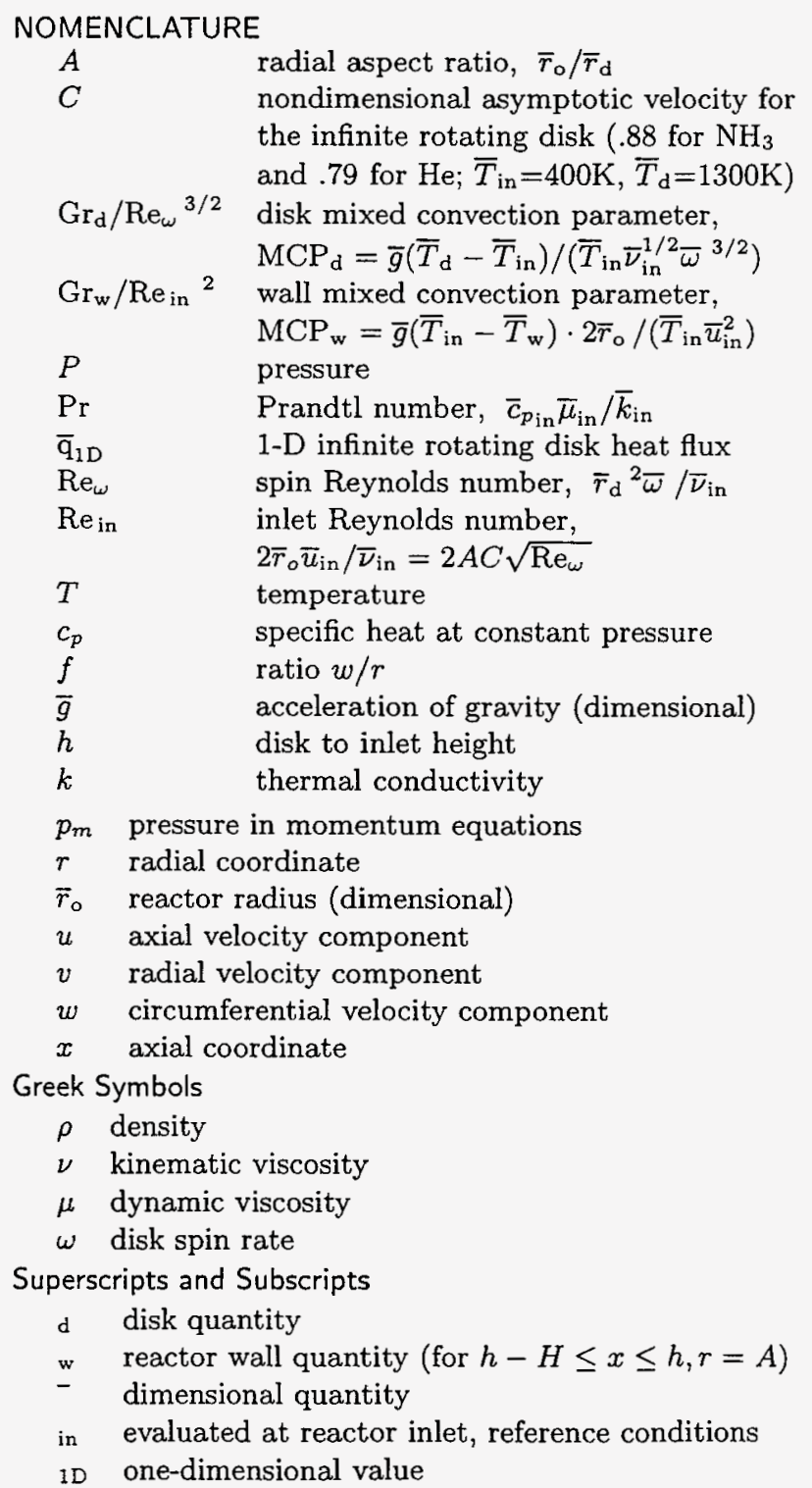

\section{REFERENCES}

Evans, G.H. and Greif, R., 1987, A Numerical Model of the Flow and Heat Transfer in a Rotating Disk Chemical Vapor Deposition Reactor, in J. Heat Transfer, vol. 109, pp.928-935.

Patnaik, S., Brown, R.A., and Wang, C.A., 1989, Hydrodynamic Dispersion in Rotating Disk OMVPE Reactors, in J. Crystal Growth, vol. 96, pp.153-174.

Chou, F. and Gong, S., 1994, Effect of Wall Cooling on the Flow Regime Map in a Rotating-Disk CVD Reactor, in J. Chemical Vapor Deposition, vol. 3, pp.47-64.

Palmateer, S.C., Groves, S.H., Wang, C.A., Weyburne, D.W. and Brown, R.A., 1987, Use of Flow Visualization and Tracer Gas Studies for designing an INP/InGaAsP OMVPE Reactor, in J. Crystal Growth, vol. 83, pp.202210.

Winters, W.S., Evans, G.H. and Greif, R., 1997, Mixed Binary Convection in a Rotating Disk Chemical Vapor Depositon Reactor, in Int. J. Heat Mass Transfer, vol. 40, pp.737-744.

Evans, G.H. and Greif, R., 1988, Forced Flow Near a Heated Rotating Disk: A Similarity Solution, in Num. Heat Transfer, vol. 14, pp.373-387.

Patankar, S.V., 1980, Numerical Heat Transfer and Fluid Flow, McGraw-Hill, New York.

Winters, W.S., Evans, G.H., and Moen, C.D., 1996, CURRENT - A Computer Code for Modeling TwoDimensional, Chemically Reacting, Low Mach Number Flows, SAND97-8202 Report, October.

\begin{tabular}{|lllll|}
\hline $\begin{array}{l}\text { Carrier } \\
\text { Gas }\end{array}$ & $\frac{\mathrm{k}_{1300}}{\mathrm{k}_{400}}$ & $\frac{\mu_{1300}}{\mu_{400}}$ & $\operatorname{Pr}_{400}$ & $\operatorname{Pr}_{1300}$ \\
\hline \hline $\mathrm{NH}_{3}$ & 4.75 & 2.99 & .72 & .73 \\
$\mathrm{H}_{2}$ & 2.35 & 2.15 & .69 & .69 \\
$\mathrm{He}$ & 2.14 & 2.15 & .67 & .67 \\
$\mathrm{~N}_{2}$ & 2.58 & 2.21 & .71 & .71 \\
$\mathrm{O}_{2}$ & 2.64 & 2.23 & .71 & .71 \\
$\mathrm{Ar}$ & 2.28 & 2.28 & .67 & .67 \\
\hline
\end{tabular}

Table 1: Carrier gas properties at $400 \mathrm{~K}$ and $1300 \mathrm{~K}$.

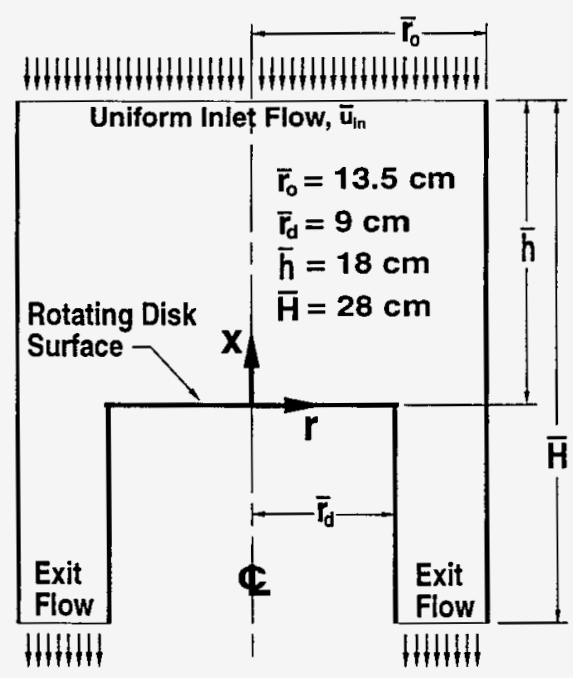

Figure 1: Reactor Geometry. 


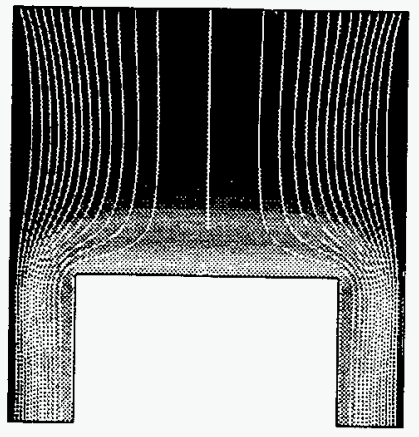

(a) Grey fill temperature contours with superimposed streamlines.

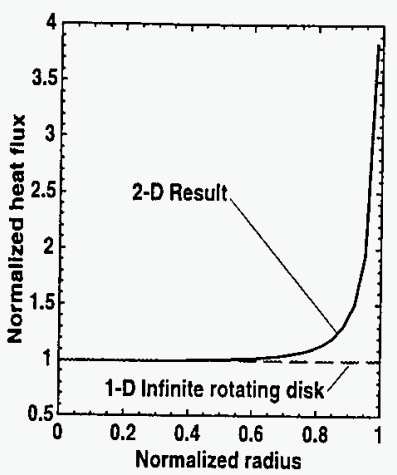

(b) Disk heat flux distribution

Figure 2: Comparison with 1-D infinite rotating disk solution for $\operatorname{Re}_{\omega}=314.5, \mathrm{MCP}_{\mathrm{d}}=1.3$, and $\mathrm{MCP}_{\mathrm{w}}=0$. Conditions: 13.5 torr, $562 \mathrm{RPM}, \overline{\mathrm{T}}_{\mathrm{d}}=1300 \mathrm{~K}, \overline{\mathrm{T}}_{\mathrm{in}}=$ $400 \mathrm{~K}, \overline{\mathrm{T}}_{\mathrm{w}}=400 \mathrm{~K},-\bar{u}_{\text {in }}=26.3 \mathrm{~cm} / \mathrm{sec}$, and $\overline{\mathrm{q}}_{1 \mathrm{D}}=$ $3.37 \times 10^{6} \mathrm{ergs} / \mathrm{sec}-\mathrm{cm}^{2}$.
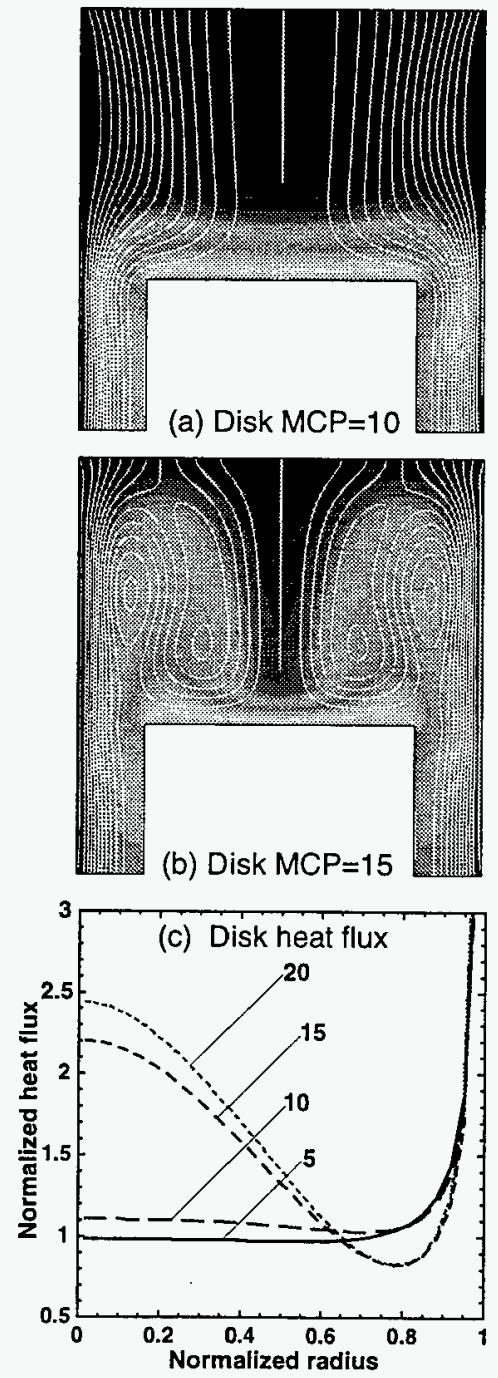

Figure 3: Influence of $\mathrm{MCP}_{\mathrm{d}}$ on flow and temperature at $\operatorname{Re}_{\omega}=314.5$. Conditions: $\overline{\mathrm{T}}_{\mathrm{d}}=1300, \mathrm{~K}, \overline{\mathrm{T}}_{\mathrm{in}}=400 \mathrm{~K}$, $\overline{\mathrm{T}}_{\mathrm{w}}=400 \mathrm{~K}$, and $\overline{\mathrm{q}}_{1 \mathrm{D}}=3.37 \times 10^{6} \mathrm{ergs} / \mathrm{sec}-\mathrm{cm}^{2} ;$ (a) 38 torr, $198 \mathrm{RPM},-\bar{u}_{\text {in }}=9.3 \mathrm{~cm} / \mathrm{sec}$, (b) 47 torr, 162 $\mathrm{RPM},-\bar{u}_{\text {in }}=7.6 \mathrm{~cm} / \mathrm{sec}$, (c) Disk heat flux distributions for 4 values of $\mathrm{MCP}_{\mathrm{d}}$.
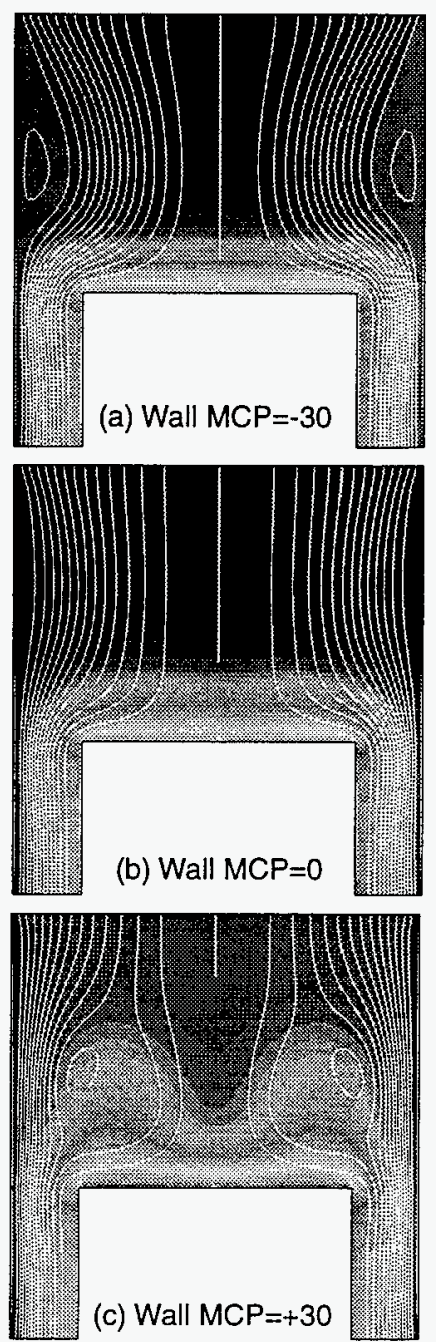

Figure 4: Influence of $\mathrm{MCP}_{\mathrm{w}}$ on flow and temperature at $\operatorname{Re}_{\omega}=314.5$ and $\mathrm{MCP}_{\mathrm{d}}=5$. Conditions: 27 torr, 281 $\mathrm{RPM},-\bar{u}_{\text {in }}=13.2 \mathrm{~cm} / \mathrm{sec}, \overline{\mathrm{T}}_{\mathrm{d}}=1300 \mathrm{~K}, \overline{\mathrm{T}}_{\mathrm{in}}=400 \mathrm{~K}$, and $\overline{\mathrm{q}}_{1 \mathrm{D}}=3.37 \times 10^{6} \mathrm{ergs} / \mathrm{sec}-\mathrm{cm}^{2}$; (a) $\overline{\mathrm{T}}_{\mathrm{w}}=479 \mathrm{~K}$, (b) $\overline{\mathrm{T}}_{\mathrm{w}}=400 \mathrm{~K}$, (c) $\overline{\mathrm{T}}_{\mathrm{w}}=321 \mathrm{~K}$.

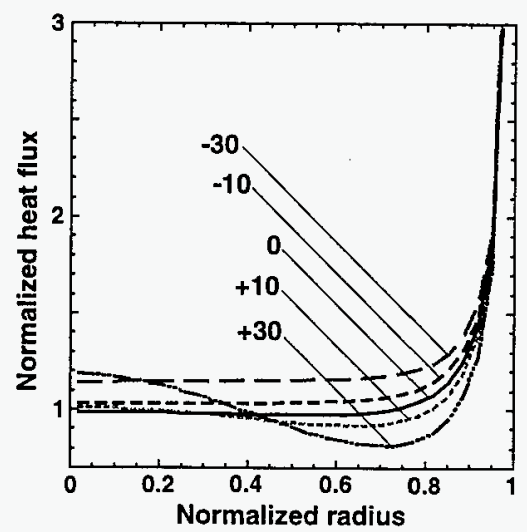

Figure 5: Influence of $\mathrm{MCP}_{\mathrm{w}}$ on disk heat flux at $\operatorname{Re}_{\omega}=$ 314.5 and $\mathrm{MCP}_{\mathrm{d}}=5$. Conditions: 27 torr, 281 RPM, $-\bar{u}_{\text {in }}=13.2 \mathrm{~cm} / \mathrm{sec}, \overline{\mathrm{T}}_{\mathrm{d}}=1300 \mathrm{~K}, \overline{\mathrm{T}}_{\mathrm{in}}=400 \mathrm{~K}$, and $\overline{\mathrm{q}}_{1 \mathrm{D}}=$ $3.37 \times 10^{6} \mathrm{ergs} / \mathrm{sec}-\mathrm{cm}^{2} ; \mathrm{MCP}_{\mathrm{w}}=-30: \overline{\mathrm{T}}_{\mathrm{w}}=479 \mathrm{~K}$, $\mathrm{MCP}_{\mathrm{w}}=-10: \overline{\mathrm{T}}_{\mathrm{w}}=426 \mathrm{~K}, \mathrm{MCP}_{\mathrm{w}}=0: \overline{\mathrm{T}}_{\mathrm{w}}=400 \mathrm{~K}$, $\mathrm{MCP}_{\mathrm{w}}=+10: \overline{\mathrm{T}}_{\mathrm{w}}=374 \mathrm{~K} \mathrm{MCP}=+30: \overline{\mathrm{T}}_{\mathrm{w}}=321 \mathrm{~K}$. 


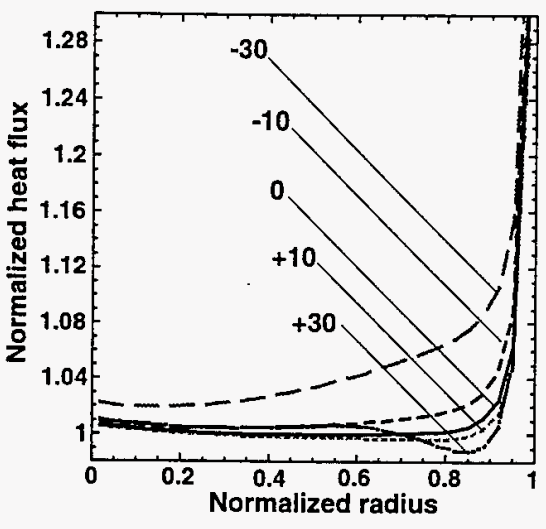

Figure 6: Influence of $\mathrm{MCP}_{\mathrm{w}}$ on disk heat flux at $\mathrm{Re}_{\omega}=$ 3145 and $\mathrm{MCP}_{d}=5$. Conditions: 152 torr, $500 \mathrm{RPM}$, $-\bar{u}_{\text {in }}=7.4 \mathrm{~cm} / \mathrm{sec}, \overline{\mathrm{T}}_{\mathrm{d}}=1300 \mathrm{~K}, \overline{\mathrm{T}}_{\mathrm{in}}=400 \mathrm{~K}$, and $\overline{\mathrm{q}}_{1 \mathrm{D}}=$ $1.07 \times 10^{7} \mathrm{ergs} / \mathrm{sec}-\mathrm{cm}^{2} ; \mathrm{MCP}_{\mathrm{w}}=-30: \overline{\mathrm{T}}_{\mathrm{w}}=424 \mathrm{~K}$, $\mathrm{MCP}_{\mathrm{w}}=-10: \overline{\mathrm{T}}_{\mathrm{w}}=406 \mathrm{~K}, \mathrm{MCP}_{\mathrm{w}}=0: \overline{\mathrm{T}}_{\mathrm{w}}=400 \mathrm{~K}$ $\mathrm{MCP}_{\mathrm{w}}=+10: \overline{\mathrm{T}}_{\mathrm{w}}=392 \mathrm{~K}, \mathrm{MCP}_{\mathrm{w}}=+30: \overline{\mathrm{T}}_{\mathrm{w}}=376 \mathrm{~K}$.
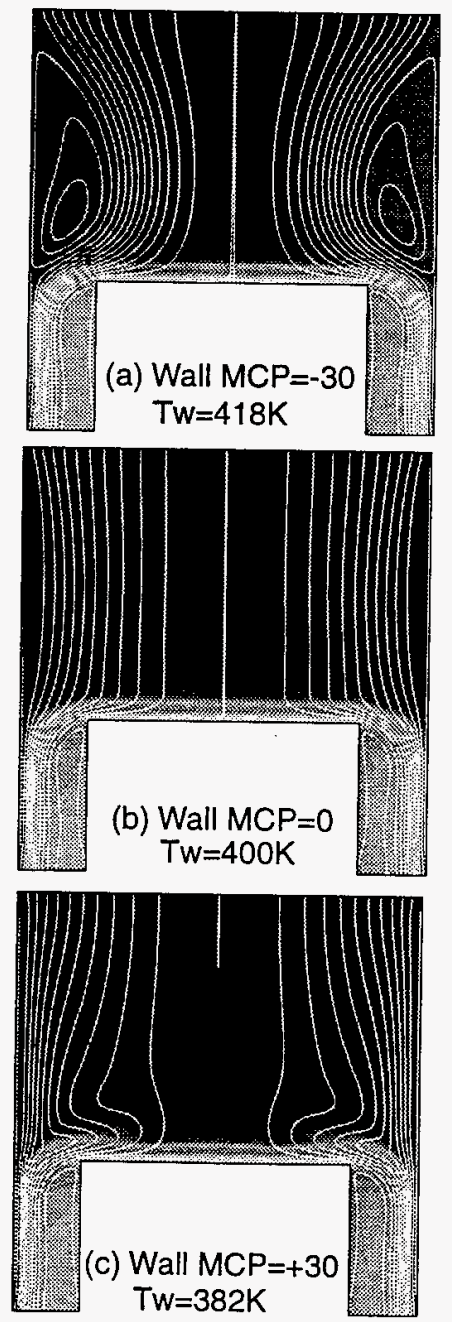

Figure 7: Flow field influence of $\mathrm{MCP}_{\mathrm{w}}$ at $\mathrm{Re}_{\omega}=3145$ and $\mathrm{MCP}_{\mathrm{d}}=7$. Conditions: 180 torr, $423 \mathrm{RPM},-\bar{u}_{\mathrm{in}}=$ $6.3 \mathrm{~cm} / \mathrm{sec}, \overline{\mathrm{T}}_{\mathrm{d}}=1300 \mathrm{~K}, \overline{\mathrm{T}}_{\mathrm{in}}=400 \mathrm{~K}$, and $\overline{\mathrm{q}}_{1 \mathrm{D}}=1.07 \times$ $10^{7} \mathrm{ergs} / \mathrm{sec}-\mathrm{cm}^{2}$.

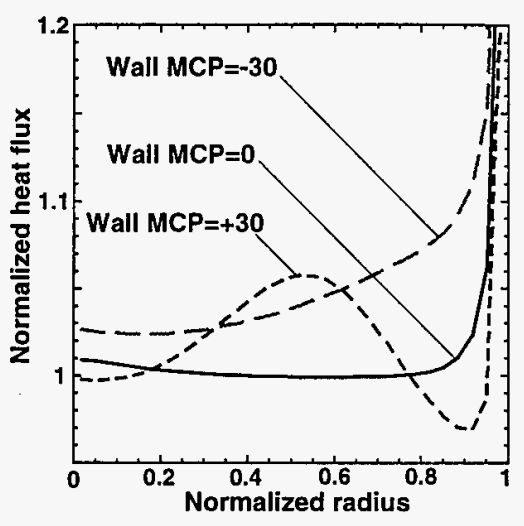

Figure 8: Heat flux influence of $\mathrm{MCP}_{\mathrm{w}}$ at $\mathrm{Re}_{\omega}=3145$ and $\mathrm{MCP}_{\mathrm{d}}=7$. Conditions: 180 torr, $423 \mathrm{RPM},-\bar{u}_{\text {in }}=$ $6.3 \mathrm{~cm} / \mathrm{sec}, \overline{\mathrm{T}}_{\mathrm{d}}=1300 \mathrm{~K}, \overline{\mathrm{T}}_{\mathrm{in}}=400 \mathrm{~K}$, and $\overline{\mathrm{q}}_{1 \mathrm{D}}=1.07 \times$ $10^{7} \mathrm{ergs} / \mathrm{sec}-\mathrm{cm}^{2}$.
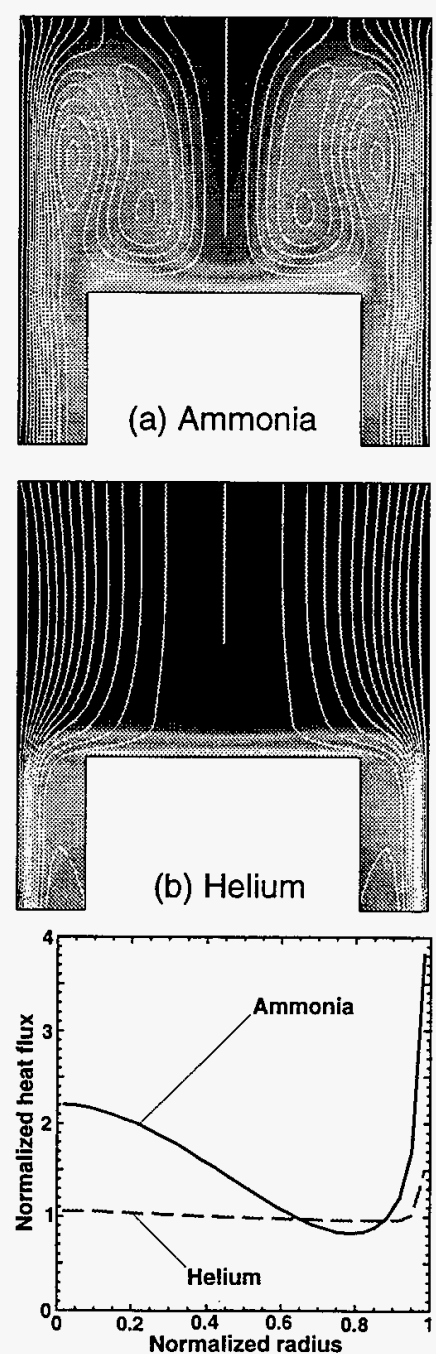

(c) Disk MCP $=15$

Figure 9: Influence of transport properties at $\operatorname{Re}_{\omega}=314.5$ for $\mathrm{MCP}_{\mathrm{w}}=0$ and $\mathrm{MCP}_{\mathrm{d}}=15 . \mathrm{NH}_{3}$ conditions: 46.7 torr, $162 \mathrm{RPM},-\bar{u}_{\text {in }}=7.6 \mathrm{~cm} / \mathrm{sec}, \overline{\mathrm{T}}_{\mathrm{d}}=1300 \mathrm{~K}, \overline{\mathrm{T}}_{\mathrm{in}}=$ $400 \mathrm{~K}, \overline{\mathrm{T}}_{\mathrm{w}}=400 \mathrm{~K}$ and $\overline{\mathrm{q}}_{1 \mathrm{D}}=3.37 \times 10^{6} \mathrm{ergs} / \mathrm{sec}-\mathrm{cm}^{2}$; He conditions: 277 torr, $163 \mathrm{RPM},-\bar{u}_{\text {in }}=6.8 \mathrm{~cm} / \mathrm{sec}$, $\overline{\mathrm{T}}_{\mathrm{d}}=1300 \mathrm{~K}, \overline{\mathrm{T}}_{\mathrm{in}}=400 \mathrm{~K}, \overline{\mathrm{T}}_{\mathrm{w}}=400 \mathrm{~K}$ and $\overline{\mathrm{q}}_{1 \mathrm{D}}=8.79 \times$ $10^{6} \mathrm{ergs} / \mathrm{sec}-\mathrm{cm}^{2}$. 
Report Number (14) $\frac{\text { SAND--98-8785C }}{\text { CONF-980S06 }}$

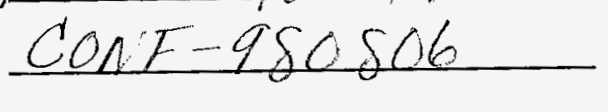

Publ. Date (11)

Sponsor Code (18)

UC Category (19)

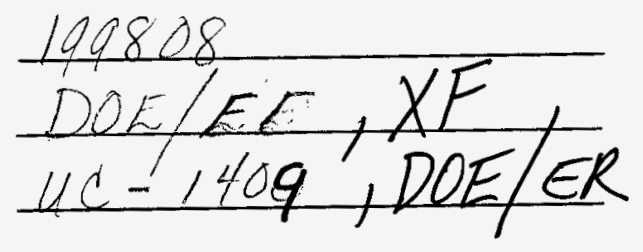

19980707078

DTIC QEALITT INAPECTED 1 